\title{
New Technologies for Information and Communication, PWM Remote Experimenting and 3G Networks as Teaching Support
}

\author{
http://dx.doi.org/10.3991/ijep.v2i1.1908 \\ J.B. Silva ${ }^{1}$, V. Gruber ${ }^{2}$ and R. Marcelino ${ }^{2}$ \\ ${ }^{1}$ Universidade Federal de Santa Catarina, Araranguá, Brasil \\ ${ }^{2}$ Faculdade SATC, Criciúma,Brasil
}

\begin{abstract}
Remote experiments may be an important tool to implement new technologies in the teaching/learning process, since it enables experimenting with real plants, essential to consolidate the concepts acquired in the theoretical classes, especially in technical and scientific disciplines. This article presents the "modulator PWM" remote experiment, its operational architecture and construction. It seeks to demonstrate its integration with theory and the use of the 3G cellular network as a communications channel for remote experimenting. The PWM modulators are often used in disciplines of higher education courses in electrical engineering, telecommunications and electronics. This article shows that it is possible to perform the practical activity completely remotely, via 3G cellular networks or through the internet to access the experiment and perform the experiments needed to fully understand the theories of the PWM modulator. This article is a further initiative for remote experiments in the world of different engineering specialties, involving the cellular networks that are rapidly expanding at this time.
\end{abstract}

Index Terms-Cellular networks (3G), Remote Experiment Modulator (PWM) and Virtual learning environment.

\section{INTRODUCTION}

The new technologies for information and communication (NTIC) have had an impact on all fields of people development, broadening their view of the world. Consequently, they have also modified access to information and interpersonal relations. In the educational environment a major change is perceived in the profiles of teachers and students who exert pressure for models in educational action to be permanently updated and adapted to these new learning scenarios, where the NTIC constitute an endless source of alternatives. The teaching and learning paradigms have undergone significant changes in the last few decades and this has allowed a partial evolution of educational models.

In order to learn science and acquire scientific culture, it is essential to perform experimental work in appropriately equipped laboratories. However, not all students have access to this equipment. At the various levels of education there are experimental activities as part of the school year, in which the students must "confirm theories", thus enabling a convergence between theory and practice. These experimental activities, however, have been replaced by demonstrations performed by the teacher to the entire class, since many institutions of education (IE) do not have appropriately equipped laborato- ries, or they are not available to work with a large number of students. In particular, when training future engineers, the use of tools for an NTIC environment in laboratory practices allows the configuration of a new temporal distribution of activities, with greater emphasis on thinking about experimentation, interpretation of results and writing conclusions.

In the literature we find three different types of laboratory commonly used in scientific and technological teaching: the hands-on laboratory, the remote experimenting laboratory and the virtual laboratory. The hands-on laboratory is the one conventionally used in face-to-face courses, in which the student manipulates the experimental materials directly in the same space and time as his classmates and in the presence of the teacher. The remote experimental laboratory is distant from the student when it is used, but allows the student to control the tools and devices that are not in the same place as he is, at a distance, through some kind of interface that mediates between the student and the devices and equipment. Lastly, the virtual laboratory is the one based on simulations, in which the student does not interact with instruments and devices, but with computer representations of reality. [1] The remote experimentation and simulated laboratories can be at least as effective as the traditional (hands-on) ones in teaching specific concepts.

In this article we show the use of NTIC accessing a remote experiment online and using $3 G$ cellular networks as a communication channel. The remote experiment implemented is an electronic circuit that generates the PWM (Pulse Width Modulation) signal. The use of mobile telephones has become routine in people's lives, since it allows mobility. Because it allows faster data transmission, 3G technology enables organizations or teaching institutions to offer increasingly low cost service packages. Among the services provided are broad band internet, TV on cell phones, 3D games, video and music downloads. [2] Another service that has grown is to improve knowledge without leaving home using the current technologies, i.e., Distance Teaching. The latter is currently highly sought after because of mobility.

\section{APPLIED TECHNOLOGIES}

The technologies used to develop this work are: Moodle, as a learning management system, 3G cellular mobile telephony as a connection to the medium and the MSW-Microserver Web platform for self-produced data acquisition, used to send and receive the information re- 
quested by the remote experiment user. Further details will be presented below to help understand the technologies used.

\section{A. Moodle platform}

Currently there are many environments that gather a number of resources to create and structure on-line courses. These environments are also known as Learning Management System (LMS). The name Moodle is an acronym of Modular Object Oriented Developmental Learning Environment and it is a Course Management System (CMS) through the Internet. One of its main advantages is that it is open source, i.e., it has an open code, allowing any user with programming knowledge to modify and adapt the environment according to their own needs.

The concept and development of Moodle are guided by "constructionist social pedagogy”. This is subdivided into four large related concepts: constructivism based on the viewpoint that people build new knowledge when they interact with their environment. Constructionism advocates that learning occurs when one constructs something for other people to try. Social Constructivism is when a group creates something collaboratively for other people to learn. [3].

Nowadays this platform is widely used the world over, by universities, schools, course instructors, teachers and even businesses. The great success of Moodle is also due to the fact that the system code is available for developers in several parts of the world and they contribute new applications to the program, so that the system is now one of the most used in distance courses.

Moodle works without any modification in Unix, Linux, Windows, Mac OS X, Netware and any other system that supports the PHP language. It can thus be included in most hosting providers the data are stored in a single database. They work most efficiently with MySQL and PostgreSQL, but can also be used with Oracle, Access, Interbase, ODBC and others.

\section{B. Micro Web Server (MWS)}

The data acquisition model of this system is called the Micro Web Server (MWS), and it is seen in Figure 1. The MWS, built at RExLab, can be described as an autonomous device that can connect electric devices to an Ethernet system, based on a low cost and low consumption microcontroller, using protocol TCP/IP for data communication. This allows acquiring, controlling and monitoring these devices remotely, safely, effectively and economically, by using a standard Internet browser. The functionality of MWS can be easily extended by adding applications that will provide it with the capacity to monitor and/or control devices. For this purpose, MWS allows using JavaScript (embedded or in HTML code, or as separate files) and Java applets, together with HTML code, CGI routines and images. In this way, accessing the web page that contains these codes, the user will be able to access the current status of the device controlled by MWS, or the environment that it monitors. MWS may be seen in figure 3 and is currently built at a cost of US\$29.30, a power consumption in normal operational mode of 40mA and size $82 \mathrm{~mm}$ x $94 \mathrm{~mm}$. [4]

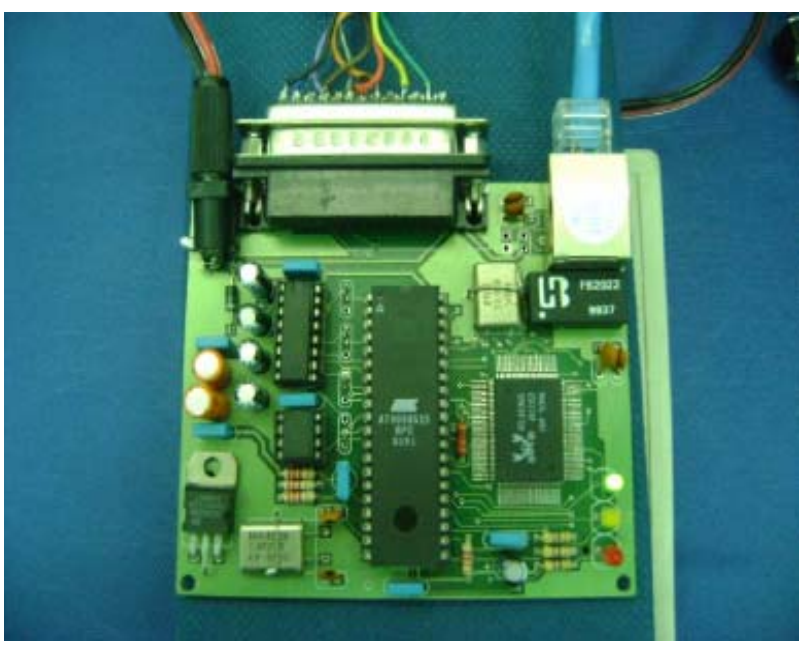

Figure 1. Web Micro Server - MWS

\section{C. $3 G$ cellular mobile telephony}

The 3G technology is used by the third generation of mobile telephony. The first was the analog cellular phones and the second the digital ones. The services provided are broadband internet, TV on the cell phone, 3D games, faster download of music and videos. Computers (Desktop or Notebook) are connected to the Internet using the cellular phone itself as a modem, a cellular phone in the form of a PCMCIA board, or a small 3G modem the size of a conventional cell phone that connects to the computer through a USB Port.[5]

The 3G technology offers a connection speed comparable to a conventional broad band, but without a fixed phone. It is not necessary to pay the provider, and the user can connect directly to the internet at any place, at any time, because it is a technology in a mobile communication apparatus.

The 3rd Generation (3G) of cellular networks offers data services with high transmission rates. The initial objectives established by International Mobile Telecommunications IMT-2000 (UIT) were $2 \mathrm{Mbit} / \mathrm{s}$ in indoor environments with low mobility. Table 1 shows the two main standards for $3 G$ networks and their respective access bands.

TABLE I.

STANDARDS FOR A 3G CELLULAR NETWORK

\begin{tabular}{|l|c|c|}
\hline & UMTS & CDMA 2000 \\
\hline Radio Interface & WDCMA/HSDP & EV-DO \\
\hline Carrier band & $5 \mathrm{MHz}$ & $1,25 \mathrm{MHz}$ \\
\hline $\begin{array}{l}\text { Development of the operators } \\
\text { who use it }\end{array}$ & GSM & CDMA \\
\hline $\begin{array}{l}\text { Agency that defines } \\
\text { standardization }\end{array}$ & $3 \mathrm{GPP}$ & $3 \mathrm{GPP} 2$ \\
\hline
\end{tabular}

The data transmission rates for the $3 G$ network are designated through the Universal Mobile Telecommunications System (UMTS) standard, which is the evolution of the GSM networks that use the Wideband CDMA (WCDMA) and its developments as a radio interface. Table 2 shows the transmission rates for the current $3 \mathrm{G}$ protocols. 
TABLE II.

TYPE SIZES FOR CAMERA-READY PAPERS

\begin{tabular}{|l|c|c|c|c|}
\hline \multicolumn{1}{|c|}{-} & WCDMA & HSDPA & HSUPA & HSPA \\
\hline $\begin{array}{l}\text { Specifation } \\
\text { (Releases) }\end{array}$ & Rel-99 & Rel-5 & Rel-6 & Rel-7 and 8 \\
\hline $\begin{array}{l}\text { Max, possible } \\
\text { data Rate } \\
\text { (DW/UP) }\end{array}$ & $\begin{array}{c}384 / 384 \\
\text { (Kbits/s) }\end{array}$ & $\begin{array}{c}7,200 / 384 \\
\text { (Kbits/s) }\end{array}$ & $\begin{array}{c}7.2 / 5.8 \\
(\text { Mbits/s) }\end{array}$ & $\begin{array}{c}40 / 10 \\
\text { (Mbits/s) }\end{array}$ \\
\hline $\begin{array}{l}\text { Mean data } \\
\text { Rate }\end{array}$ & $\begin{array}{c}200 \text { at 300 } \\
\text { (Kbits/s) }\end{array}$ & $\begin{array}{c}400 \text { at 700 } \\
\text { (Kbits/s) }\end{array}$ & - & - \\
\hline
\end{tabular}

* Dw: Down Link (ERB->Celular); Up: Up Link (Celular->ERB). The HSDPA has been implemented with peak rates of $1.8 \mathrm{Mbit} / \mathrm{s}, 3,6 \mathrm{Mbit} / \mathrm{s}$ and $7,2 \mathrm{Mbit} / \mathrm{s}$

The column width is $82 \mathrm{~mm}$ (3.23 in). The space between the two columns is $6 \mathrm{~mm}(0.24$ in). Paragraph indentation is $3.5 \mathrm{~mm}(0.14 \mathrm{in})$.

\section{PWM - Pulse Width Modulation}

This modulator operates in such a way that it varies the pulse width of the carrier, according to the modulating signal, maintaining the range and time interval of the pulses constant. The basic principle for a PWM modulator is to convert a range variation linearly into variation of the time elapsed between two events. [6]

The following PWM modulation parameters will be shown: Signal of Reference; Signal of Carrier; Modulation; Applications.

\section{1) Signal of Reference}

The signal of reference is a voltage signal that may be continuous, as seen in figure 2 , or alternate, as shown in figure 3. This voltage signal called signal of reference, is used in a way that compares it with the signal of the carrier to generate the exit voltage image wanted. The continuous voltage signal of reference is used in the CC-CC converters, figure 4 .

\section{2) Carrier signal}

The carrier signal is a high frequency signal responsible for defining the frequency of switching and cyclic ratio. According to the Nyquist theorem - theorem of sampling - the carrier's frequency must be at least twice as large as the maximum frequency of the signal of reference, but in practice, it must be at least ten times larger to achieve a good reproduction of the signal at the exit from the converter.

This signal will be responsible for the switching frequency of the switches (semiconductors) of the power drive circuit. A saw-tooth signal (figure 4) can be used or a triangular one (figure 5).

\section{3) Modulator}

The modulator is a circuit, in this case an operational amplifier seen in figure 6, responsible for comparing the signal of reference to the carrier. The exit signal from the modulator is the PWM signal, which changes according to the range of the signal of reference compared to the carrier signal.

The signal of reference is sine wave in the CC-AC converters, since alternate voltage is desired at the exit. Therefore, a signal of reference must be used with the same characteristics of the signal desired at the exit, as shown in figure 3 .

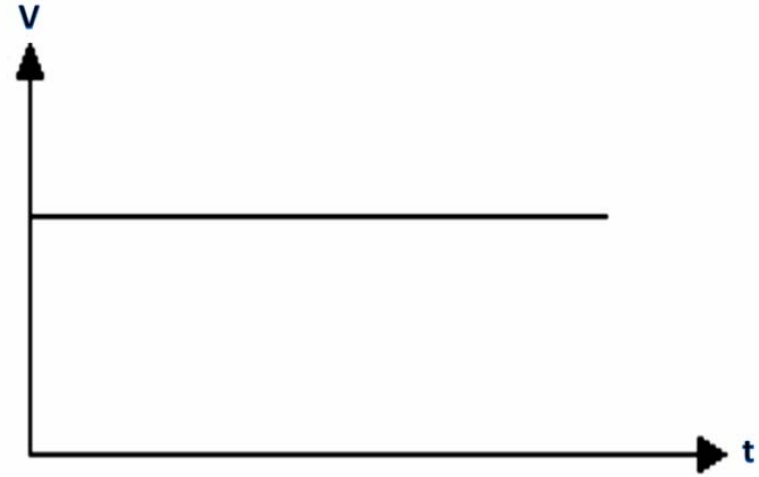

Figure 2. Signal of Reference for a CC-CC converter

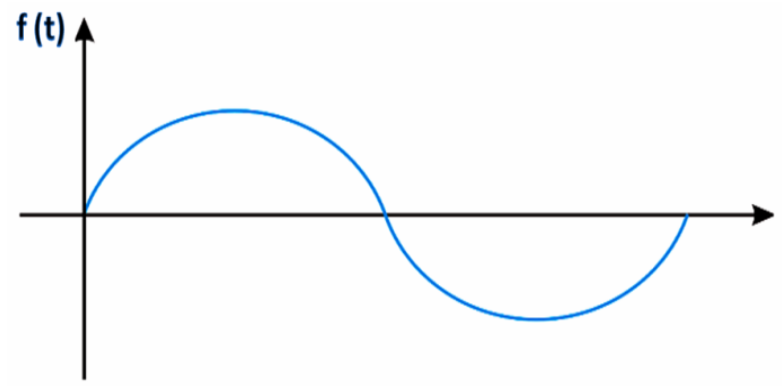

Figure 3. Signal of Reference for a CC-AC Converter

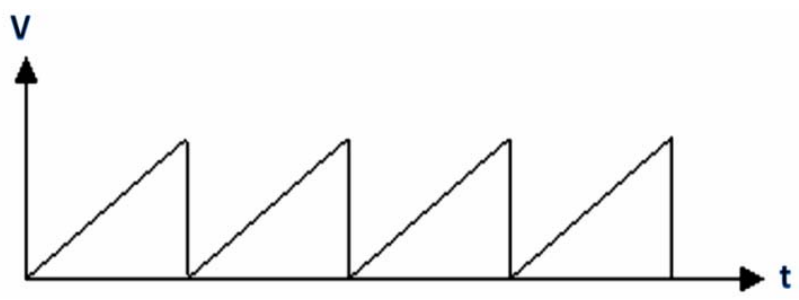

Figure 4. Sawtooth wave

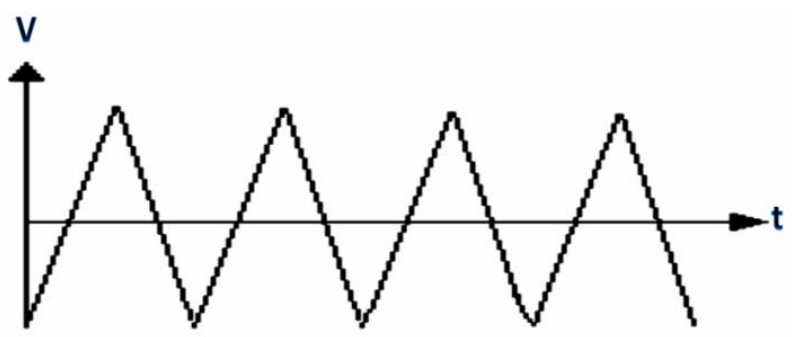

Figure 5. Triangle wave

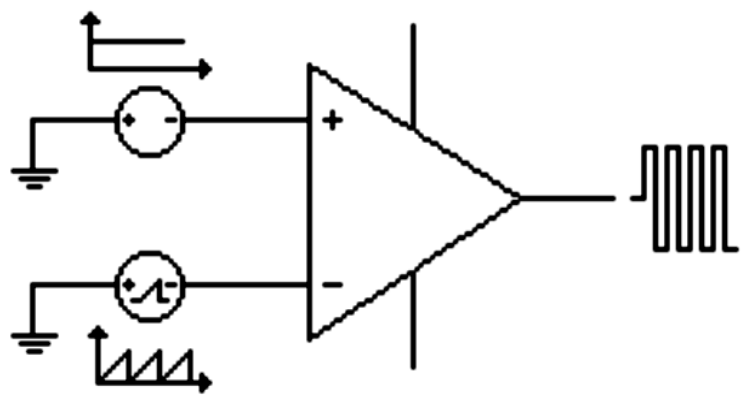

Figure 6. Generation of the Modulated Signal 


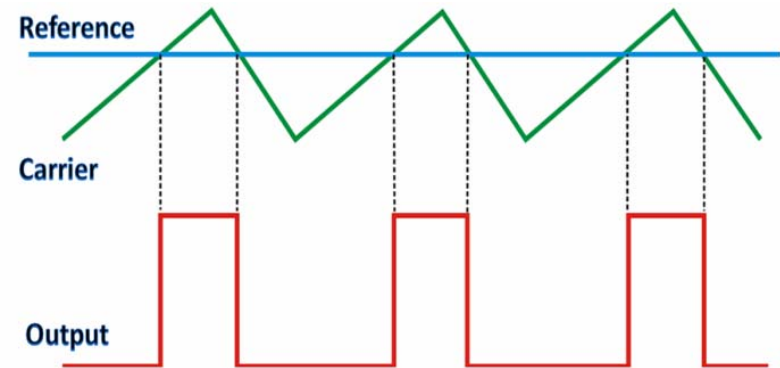

Figure 7. Outputsignal from the modulator: CC-CC Converter

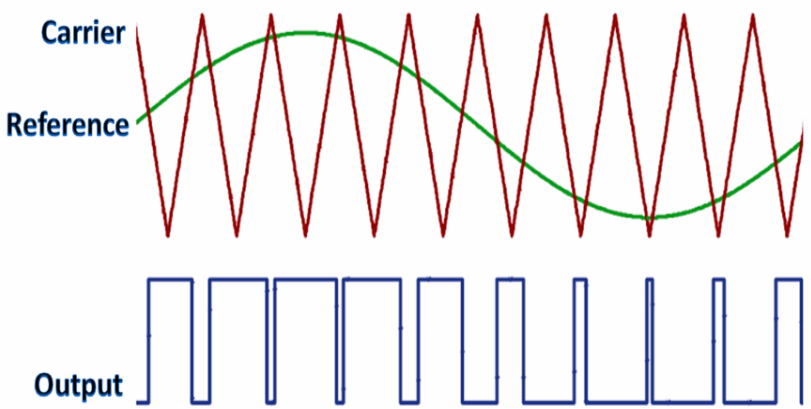

Figure 8. Outputsignal from the modulator: CC- AC Converter

Figures 7 and 8 show the signals at the entry and exit from the comparator for CC-CC converters, where the reference is a continuous signal and for CC-AC converters, where the reference is sine wave.

4) Where is it used?

The digital PWM is a circuit that is often used as an interface for the exit from microcontrollers, since it has several uses, such as that of a D/A converter, switched sources, switch control, dimmers [10]. It is also used in switched audio amplifiers and in velocity controls for continuous current motors. [11]

\section{IMPLEMENTATIONS}

All of the PWM modulator theory is available on the Moodle Platform, i.e., project presentation, objectives, introduction , modulator, modulation parameters and the explanation of how the experiment works, and a link where there will be access to the remote experiment (Figure 9).

After the theoretical part, it will be necessary for the user/visitor to click on the "PWM Remote Experiment”(Experimento Remoto PWM) link, where he will be transferred to the page where the experiments are scheduled (Figure 10) .

\section{A. Remote Experiment}

Figure 11 shows the PWM remote experiment set up at SATC College in the city of Criciúma, Brazil.

A set of hardware elements operates the remote experiment. The waveforms generated can be followed in real time through a virtual oscilloscope.

Through the internet the user can change the PWM parameters and follow the events. A miniventilator installed in the system, together with an electronic circuit, allow a visual response to the ventilator velocity according to the pulse widths generated by PWM.

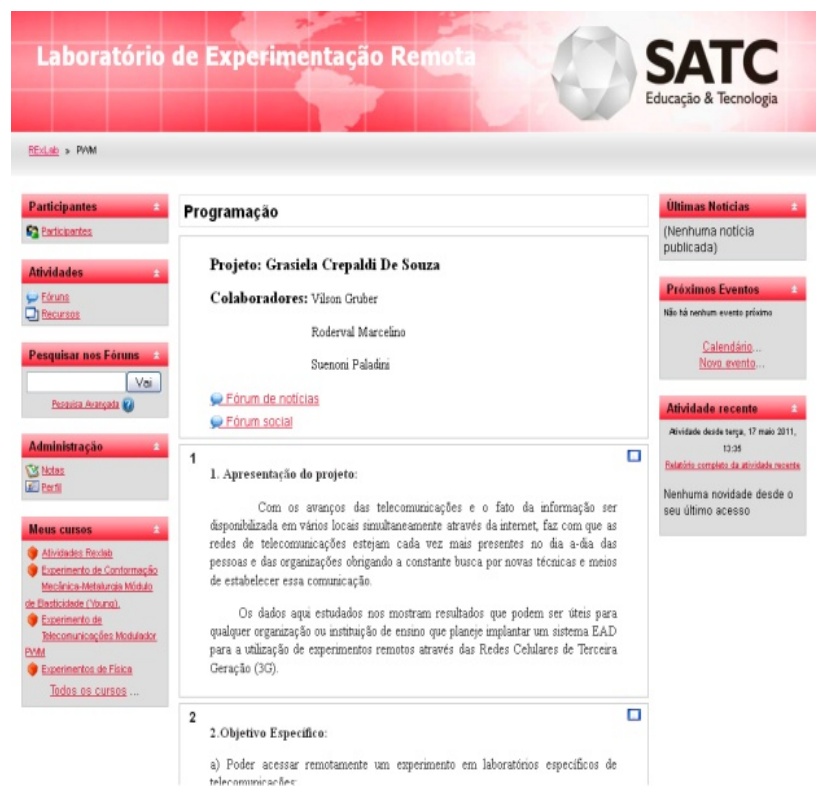

Figure 9. PWM remote experiment set up at the SATC college

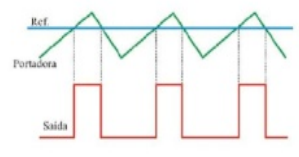

Figura 3- Sinal do Moduludor

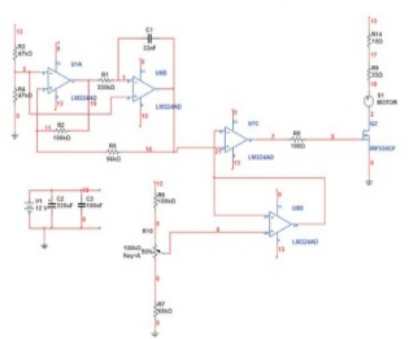

DO OUEE UMM POTENCIÓNETRC (1) Experimento Remoto PWM

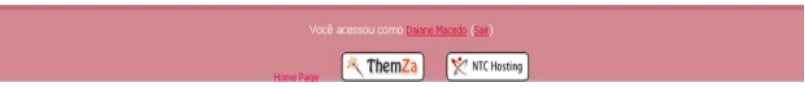

Figure 10. Moodle platform structure with the theoretical base of the experiment

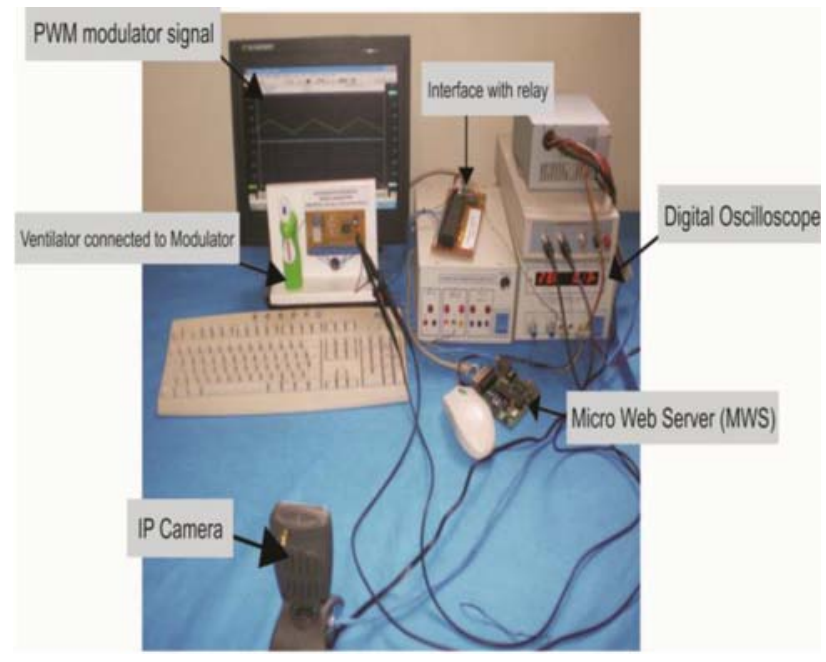

Figure 11. Link to access the experiment 
A webcam follows everything that is happening making the waveform and ventilator on-line velocity images available. An interfacing board using relays changes the reference to control the PWM. This board changes its action via the Web, according to the user's changes.

\section{B. $3 G$ Cellular Network}

Internet by $3 \mathrm{G}$ networks was used to access the experiment remotely. In figure 12 we can see an illustration of the system implemented.

The user/visitor connects to the virtual laboratory via internet IP, or through the 3G cellular telephony networks. Communication between what is real and what is virtual will be done by the MSW together with an interface with relay which is responsible for switching the ports. Generally, the $3 G$ cellular network has proved to function effectively, although, in fact. The system also did not require too much of it. The one great inconvenience is the instability of cellular networks in Brazil, which often drop the connection.

\section{Scheduling screen}

Since the RExlab portal - SATC has other remote experiments, AA scheduling system is available. A Box shows the experiments that are free at the time, and those that are in use. Based on this image, (Figure 13) the user can schedule the day and time they wish.

The time allocated is 30 minutes per experiment but the number of scheduling per user in the same experiment is not limited, i.e. if they wish to schedule two successive times for the same experiment, there is nothing to prevent it.

Later, during the scheduled time, all one has to do is click on "Access experiment now", which is below the experiment Box on the scheduling page, and visualize the experiment remotely, as shown in figure 14.

In order for the experiment to become even more visible and interactive, the communication system has a ventilator at the end of the circuit that is controlled by the PWM modulator. Frequencies of $30-200 \mathrm{~Hz}$ are normally used.

Figure 15 shows the ventilator connected to the PWM modulator circuit, where the modulator signal will control its velocity.

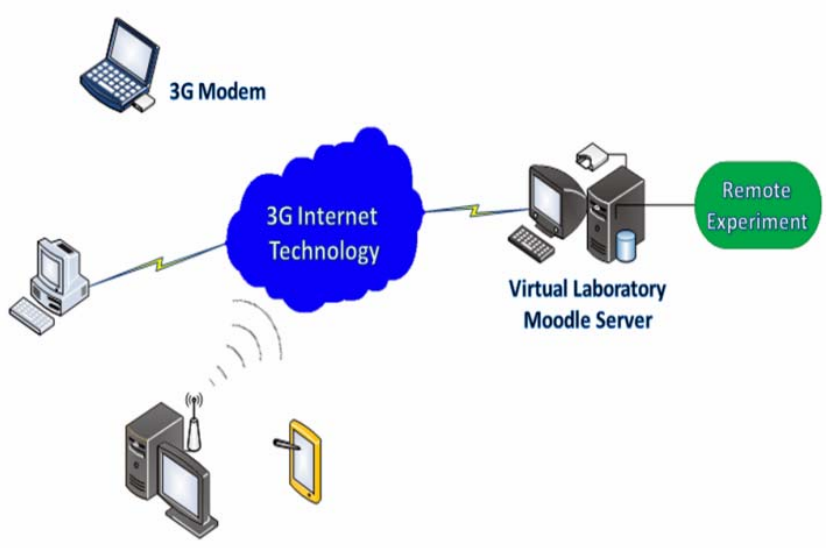

Figure 12. Link to Illustration of the distance education system

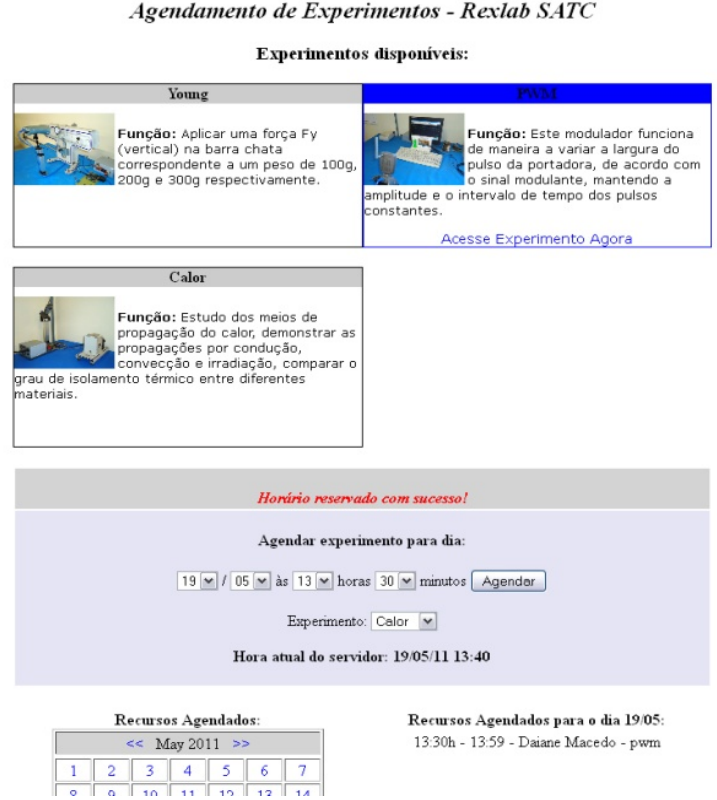

Figure 13. Layout of the scheduling page

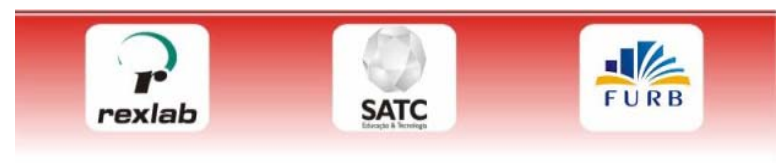

Modulador PWM

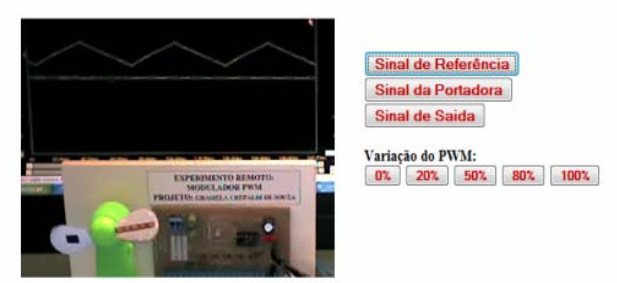

Funçâo: Este modulador funciona de maneira a variar a largura do pulso da portadora, de acordo com o sinal modulante, mantendo a amplitude $e \mathrm{o}$ intervalo de tempo dos pulsos constantes.

(1) Intemet| Protected Mod,

Figure 14. PWM remote experiment via internet

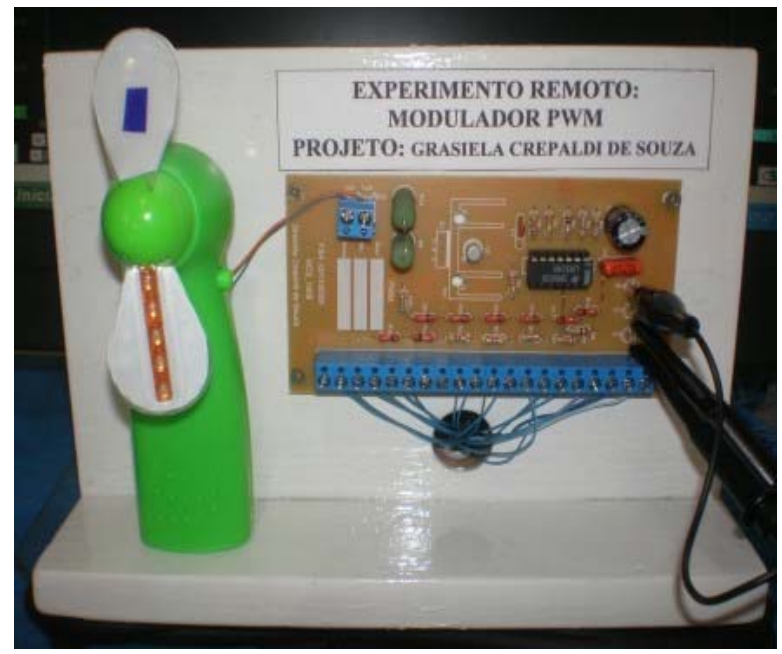

Figure 15. Ventilator connected to the PWM modulator remote experiment via internet 


\section{CONCLUSION}

In this paper we present the technological feasibility of remote experiments in an application for study in the field of engineering. Several factors came together to motivate us to create and present this work. If, on the one hand, the diversity of existing resources and tools provided within the sphere of NTICs has increased the possibilities of accessing and manipulating information and generating knowledge, this implies developing new educational strategies, a new way of teaching and new pedagogical and philosophical theories. Remote experiments provide learning benefits to any person who has access anywhere in the world, simply by using a 3G cellular network.

The flexibility of this new possibility of teaching through remote experiments brings the teaching institutions closer to people who cannot dedicate local time to learning. Applications via 3G cellular network with the new distance education techniques will have a positive impact on education, enabling thousands of accesses through these networks. By sharing experiments, distance will also mean a reduction of financial costs, since a single laboratory will be able to provide service to classrooms worldwide.

\section{REFERENCES}

[1] J. Corter et al. Constructing reality: a study of remote, hands-on, and simulated laboratories. ACM Transactions on ComputerHuman Interaction. Vol 14, No 2, agosto 2007.

[2] W. Lee.Mobile Cellular Telecommunications Systems. New York, USA .McGraw-Hill Book Company. 2006.

[3] M. Dougiamas, Moodle; a case study in sustainability[Online]. Available:http://www.oss-watch.ac.uk/resources/cs-moodle.xml

[4] J. Bento Silva, "Monitoramento, Aquisição e Controle de Sinais Elétricos, via Web, Utilizando Microcontroladores”, master's the- sis, Programa de Pós-Graduação em Computação, Universidade Federal de Santa Catarina, Florianópolis, Brasil, 2002.

[5] P. Bernal, Comunicações Móveis: Tecnologias e Aplicações. São Paulo. Editora Érica. 2008. ISBN: 85-7194-898-4.

[6] M. Alencar, Telefonia Celular Digital.São Paulo: Editora Érica, 2008. 448 p. ISBN: 85-365-0017-4.

[7] J. Bento Silva,A utilização da experimentação remota como suporte à ambientes colaborativos de aprendizagem,doctoral thesis, Programa de Pós-Graduação em Engenharia e Gestão do Conhecimento, Universidade Federal de Santa Catarina, Florianópolis, Brasil, 2007.

[8] A. Tadeu Gomes, Telecomunicações: transmissão e recepção AMFM. 17. ed. Sao Paulo : Érica, 2001. iii, 415p, il.

[9] Projeto e Fabricação de um Modulador de Largura de Pulso em tecnologia CMOS Digital,. [Online]. Available: http://biblioteca.universia.net/ficha.do?id=37257189.

[10] Modulador Por Largura de Pulso, . [Online]. Available:http://www.cpdee.ufmg.br/ elt/docs/trabalhos/pwm.htm.

\section{AUTHORS}

J. B. Silva is currently a professor in the Computer Engineering department at the Universidade Federal de Santa Catarina, Araranguá, Santa Catarina, Brasil (e-mail: mjuarez.silva@ararangua.ufsc.br)

V. Gruber is currently a professor in the Computer Engineering department at theFaculdade SATC, Criciúma, Santa Catarina, Brasil (e-mail: mvilson.gruber@satc.edu.br).

R. Marcelino is currently a professor in the Computer Engineering department at theFaculdade SATC, Criciúma, Santa Catarina, Brasil (e-mail: mroderval.marcelino@satc.edu.br).

Received 19 December 2011. Published as resubmitted by the authors 17 January 2012. 